$05,11,19$

\title{
Магнитные и магнитокалорические свойства соединений $\mathrm{Ho}_{1-x} \mathrm{Y}_{x}\left(\mathrm{Co}_{0.84} \mathrm{Fe}_{0.16}\right)_{2}$
}

\author{
(C) М.С. Аникин ${ }^{1}$, Е.Н. Тарасов ${ }^{1}$, Д.С. Незнахин ${ }^{1}$, М.А. Сёмкин ${ }^{1,2}$, Н.В. Селезнёва ${ }^{1}$, \\ С.В. Андреев ${ }^{1}$, М.В. Рагозина ${ }^{1,2}$, А.В. Зинин ${ }^{1}$ \\ ${ }^{1}$ Институт естественных наук, Уральский фредеральный университет, \\ Екатеринбург, Россия \\ ${ }^{2}$ Институт физики металлов УрО РАН им. М.Н. Михеева, \\ Екатеринбург, Россия \\ E-mail: maksim.anikin@urfu.ru
}

Поступила в Редакцию 8 июля 2021 г.

В окончательной редакции 13 июля 2021 г.

Принята к публикации 16 июля 2021 г.

\begin{abstract}
Представлены результаты исследования кристаллической структуры, температурных и полевых зависимостей намагниченности, высокополевой восприимчивости и магнитокалорического эффекта (МКЭ) поликристаллических соединений $\mathrm{Ho}_{1-x} \mathrm{Y}_{x}\left(\mathrm{Co}_{0.84} \mathrm{Fe}_{0.16}\right)_{2}(x=0-1)$, в магнитных полях напряженностью до $90 \mathrm{kOe}$ и диапазоне температур 5-400 K. Из анализа температурных зависимостей намагниченности $(\sigma)$ установлено, что в зависимости от содержания иттрия $(x)$, на исследованых образцах может одновременно присутствовать от одной до трех „критических“ температур: спин-переориентационный переход $\left(T_{\mathrm{sr}}\right)$, точка магнитной компенсации $\left(T_{\mathrm{comp}}\right)$ и температура Кюри $\left(T_{\mathrm{C}}\right)$. На температурной зависимости высокополевой восприимчивости $\left(\chi_{h f}\right)$ всех образцов с $x<1$ присутствует экстремум в окрестности $100 \mathrm{~K}$, при котором наблюдается значительный МКЭ, связанный с резким изменением намагниченности редкоземельной подрешетки. Кривые температурных зависимостей изменения магнитной части энтропии $\left(\Delta S_{m}\right)$ и адиабатического изменения температуры $\left(\Delta T_{a d}\right)$ имеют сложную форму и отражают присутствующие „критические“ температуры, наблюдаемых при разных $x$.
\end{abstract}

Ключевые слова: магнитные свойства, прямой и обратный магнитокалорический эффект, адиабатическое изменение температуры, магнитный момент, фазы Лавеса, температура Кюри, точка компенсации, спинпереориентационный переход.

DOI: 10.21883/FTT.2021.11.51578.05s

\section{1. Введение}

Кубические фазы Лавеса $R T_{2}$, где $R$ - тяжелый редкоземельный металл, $T-3 d$-переходный металл, известны достаточно давно как материалы, обладающие большими значениями магнитокалорического эффекта (МКЭ) в окрестности магнитных фазовых переходов, в том числе температуры Кюри $\left(T_{\mathrm{C}}\right)$ [1-3]. В квазибинарных соединениях на их основе реализуется большое количество материалов с $T_{\mathrm{C}}$ вблизи комнатной температуры, обладающих как обычной температурной зависимостью МКЭ, например $R(\mathrm{Co}-\mathrm{Ni})_{2}[4]$, так и с плато-подобной, например $R(\mathrm{Co}-\mathrm{Fe})_{2}$ и $R(\mathrm{Ni}-\mathrm{Fe})_{2}[5,6]$. Платоподобная температурная зависимость МКЭ в соединениях $R(\mathrm{Co}-\mathrm{Fe})_{2}$ наиболее ярко выражена в соединениях с $R$, имеющих относительно низкие значения спинового магнитного момента $4 f$-электронной оболочки $\left(S_{R}\right)$. При одной и той же концентрации железа, но с разными $R(\mathrm{Gd}, \mathrm{Dy}, \mathrm{Ho}, \mathrm{Er})$, с увеличением $S_{R}$ форма температурной зависимости изменения магнитного вклада в энтропию $\left(\Delta S_{m}\right)$ трансформируется из платоподобной зависимости в кривую с явно выраженным максимумом при $T_{\mathrm{C}}$. Платоподобная зависимость МКЭ является суперпозицией пиков МКЭ при $T_{\mathrm{C}}$ и „низкотемпературного“ пика МКЭ [5], вызванного ориентационным упорядочением внешним магнитным полем магнитных моментов атомов $R$-подрешетки, частично разупорядоченных тепловыми флуктуациями, вследствие слабого межподрешеточного $f-d$ обменного взаимодействия на образцах с малыми значениями $S_{R}[7,8]$.

Для более глубокого понимания роли межподрешеточных обменных взаимодействий в образовании МКЭ в таких системах в данной работе были исследованы соединения $\mathrm{Ho}_{1-x} \mathrm{Y}_{x}\left(\mathrm{Co}_{0.84} \mathrm{Fe}_{0.16}\right)_{2}$. В данных соединениях магнитоактивный $R$-элемент (Но) заменен на „немагнитный“ - иттрий (Y), что, по нашему мнению, должно дать качественное представление о состоянии намагниченности $R$ - и $3 d$-подрешеток и роли взаимодействия $R$ - и $3 d$-ионов в формировании магнитных и магнитокалорических свойств.

\section{2. Методика эксперимента}

Поликристаллические

соединения $\mathrm{Ho}_{1-x} \mathrm{Y}_{x}\left(\mathrm{Co}_{0.84} \mathrm{Fe}_{0.16}\right)_{2}$ были выплавлены в дуговой электропечи в защитной атмосфере гелия. Для предотвращения формирования фаз богатых $3 d$-элементом, в шихту добавляли избыток гольмия и иттрия в количестве $7 \mathrm{wt} \%$ для образцов с $x=0.4$ и 0.6 , для остальных 
$x-5 \mathrm{wt} \%$. Гомогенизация сплавов была произведена в вакууме при $1271 \mathrm{~K}$ в течение суток. Фазовый анализ и уточнение параметров кристаллической структуры выполнено с помощью метода рентгеновской дифракции, с применением порошкового дифрактометра D8 Advance (Bruker) с источником излучения $\mathrm{Cu}-\mathrm{K} \alpha(\lambda=1.5406 \AA)$. Расшифровка рентгенограмм проводилась с помощью полнопрофильного метода Ритвельда с применением программного обеспечения FullProfSuite [9].

Магнитные свойства образцов исследовались на установке PPMS DynaCool (Quantum Design) в интервале температур 2-400 K в магнитном поле до $90 \mathrm{kOе}$. Прямое измерение адиабатического изменения температуры $\left(\Delta T_{a d}\right)$ осуществлялось на экспериментальной установке MagEq MMS SV3 в температурном диапазоне 80-370 K при изменении напряженности магнитного поля $(\Delta H)$ на $17.5 \mathrm{kOe}$.

\section{3. Результаты и обсуждения}

\section{1. Аттестация образцов}

На рис. 1 представлены приведенные рентгенограммы исследованных порошковых образцов $\mathrm{Ho}_{1-x} \mathrm{Y}_{x}\left(\mathrm{Co}_{0.84} \mathrm{Fe}_{0.16}\right)_{2}$ при комнатной температуре. Анализ рентгенограмм показал, что все образцы практически однофазны. Основу соединений формируют фазы Лавеса, стихеометрического состава 1:2, принадлежащие гранецентрированной кубической $F d \overline{3} m$ пространственной группе. Содержание примесных фаз (преимущественно $R_{2} \mathrm{O}_{3}$ ), для различных образцов от 0 до $2.5 \%$. Уточненные значения параметра кристаллической решетки $(a)$ представлены на рис. 3 .

\section{2. Намагниченность}

На рис. 2 представлены температурные зависимости удельной результирующей намагниченности $(\sigma)$ исследованных образцов в магнитном поле $1 \mathrm{kOe}$. Вид зависимостей $\sigma(T)$ подтверждает отсутствие примесных магнитных фаз во всей магнитоупорядоченной области температур.

Все исследуемые соединения являются двухподрешеточными ферримагнетиками [10], в которых магнитоактивные атомы гольмия в $R$-подрешетке замещаются на „немагнитный“ иттрий, постепенно уменьшая намагниченность $R$-подрешетки $\left(\sigma_{R}\right)$ до нуля. На основе анализа зависимостей $\sigma(T)$ соединенений $\mathrm{Ho}_{1-x} \mathrm{Y}_{x}\left(\mathrm{Co}_{0.84} \mathrm{Fe}_{0.16}\right)_{2}$ можно выделить 4 типа реализующихся в них магнитоструктурных состояний. Для образцов с $x \leq 0.4$ намагниченность $R$-подрешетки во всей температурной области превышает намагниченность $3 d$-подрешетки $\left(\sigma_{3 d}\right)$. На температурных зависимостях намагниченностей соединений с $x=0.60$ и 0.75 наблюдаются температуры магнитной компенсации $\left(T_{\text {сотр }}\right)$. Выше этих температур намагниченности $\sigma_{3 d}$ превышают по модулю намагниченности $\sigma_{R}$, и результирующие намагниченности этих соединений сонаправлены с намагниченностью

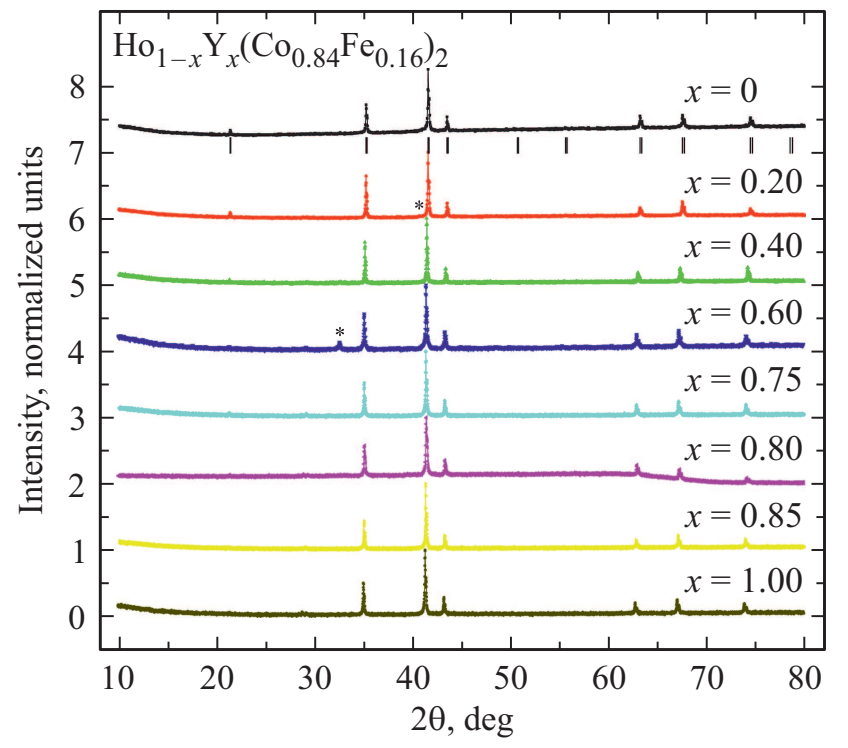

Рис. 1. Экспериментальные рентгенограммы порошковых образцов соединений $\mathrm{Ho}_{1-x} \mathrm{Y}_{x}\left(\mathrm{Co}_{0.84} \mathrm{Fe}_{0.16}\right)_{2}$. Под рентгенограммой образца с $x=0$, указаны положения брэгговских рефлексов основной фазы $R T_{2}$. Пики от примесных фаз отмечены звездочками.

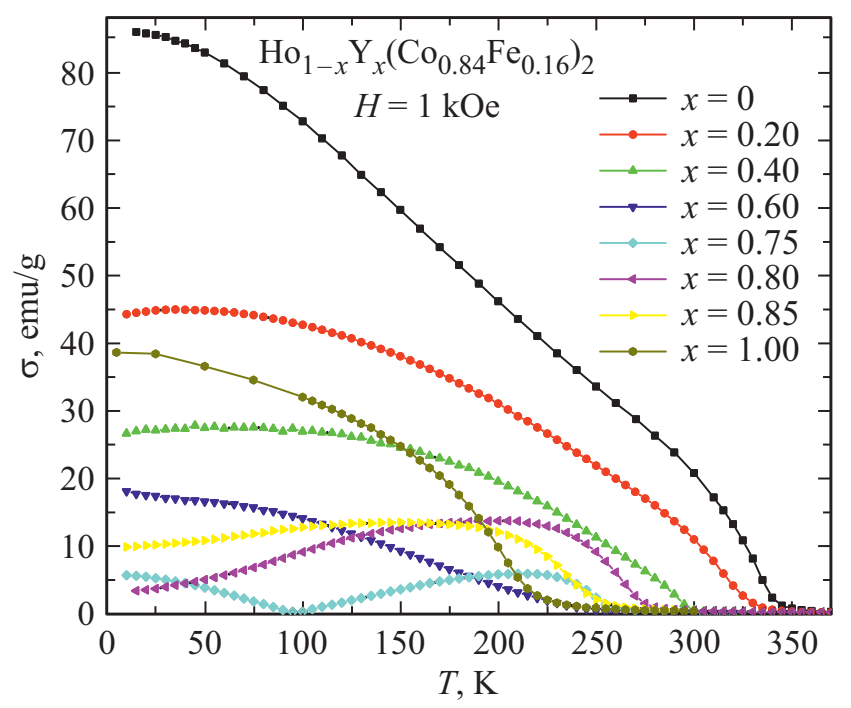

Рис. 2. Температурные зависимости удельной намагниченности образцов соединений $\mathrm{Ho}_{1-x} \mathrm{Y}_{x}\left(\mathrm{Co}_{0.84} \mathrm{Fe}_{0.16}\right)_{2}$ во внешнем магнитном поле $1 \mathrm{kOe}$.

$3 d$-подрешетки. В соединениях с $x=0.80$ и $0.85 \sigma_{3 d}$ превышает $\sigma_{R}$ во всей температурной области. При $x=1$ намагниченность $R$-подрешетки равна нулю и соединение $\mathrm{Ho}_{1-x} \mathrm{Y}_{x}\left(\mathrm{Co}_{0.84} \mathrm{Fe}_{0.16}\right)_{2}$ становится ферромагнетиком [11].

Температуры магнитных фазовых переходов и точки магнитной компенсации исследованных образцов были определены по экстремуму первой производной $d \sigma / d T$ зависимостей $\sigma(T)$, измеренных по протоколу ZFC и FC в магнитном поле 100 Ое. Полученные концентра- 


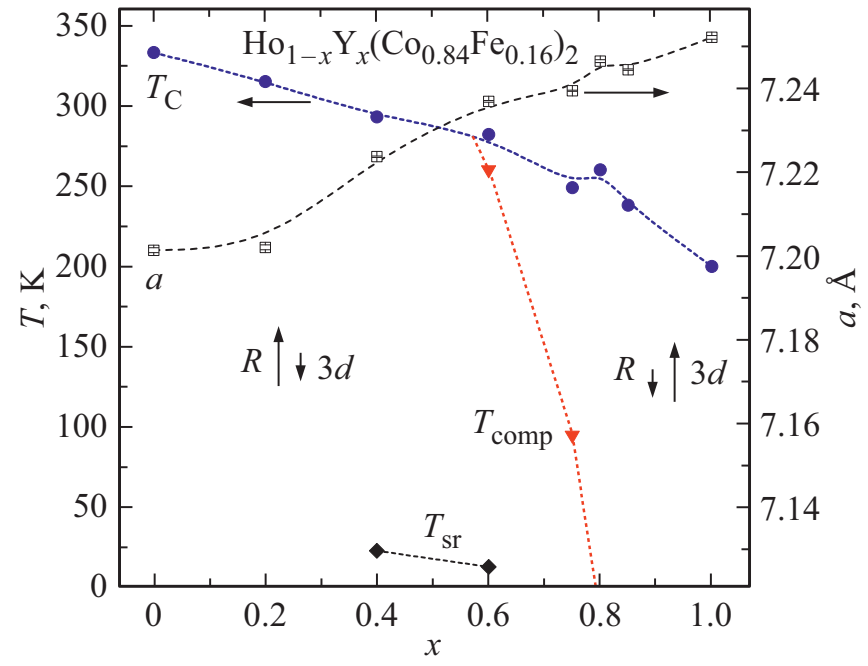

Рис. 3. Концентрационные зависимости параметра кристаллической решетки и точек магнитной компенсации $\left(T_{\text {comp }}\right)$, температур Кюри $\left(T_{\mathrm{C}}\right)$ и спиновой переориентации оси легкого намагничивания $\left(T_{\mathrm{sr}}\right)$ в соединениях $\mathrm{Ho}_{1-x} \mathrm{Y}_{x}\left(\mathrm{Co}_{0.84} \mathrm{Fe}_{0.16}\right)_{2}$. Вертикальными стрелками условно обозначены относительные намагниченности $R$ - и $3 d$-подрешеток для соответствующих областей концентраций $x$ и температур.

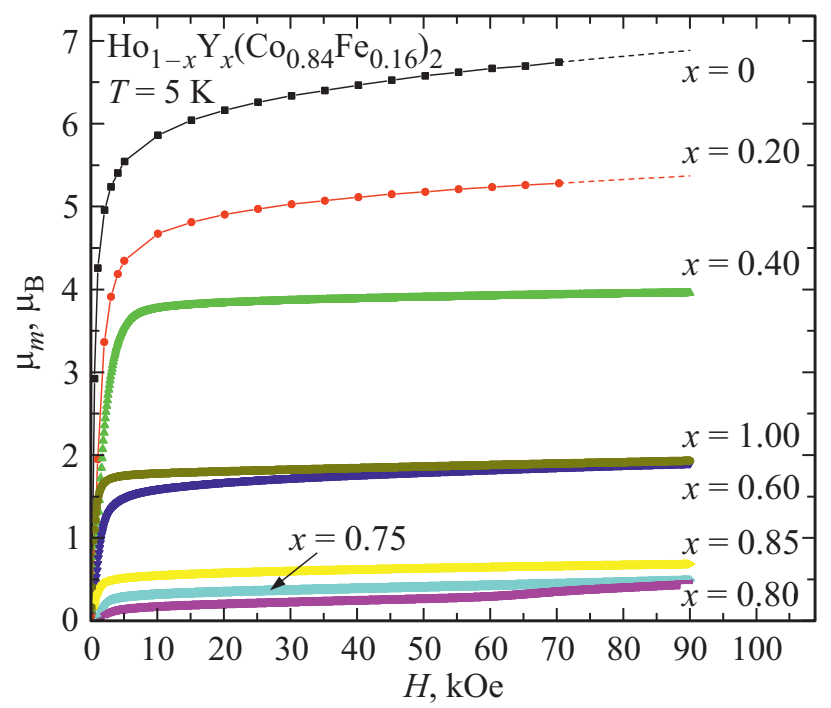

Рис. 4. Кривые намагничивания образцов соединений $\mathrm{Ho}_{1-x} \mathrm{Y}_{x}\left(\mathrm{Co}_{0.84} \mathrm{Fe}_{0.16}\right)_{2}$ измеренные при температуре $5 \mathrm{~K}$. Пунктирные линии - линейная экстраполяция данных.

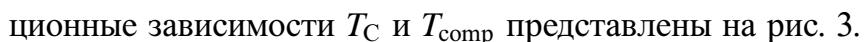
На температурных зависимостях намагниченности $\sigma(T)$ в 100 Ое образцов с $x=0.4$ и 0.6 , кроме $T_{\mathrm{C}}$ и $T_{\text {comp }}$, были обнаружены магнитные фазовые переходы при температурах 23 и $13 \mathrm{~K}$ соответственно, которые могут быть связаны с изменением оси легкого намагничивания в этих соединениях [12-14], т. е. при данных температуpax происходит спин-переориентационный переход $\left(T_{\mathrm{sr}}\right)$. Температуры $T_{\text {sr }}$ указаны на рис. 3 .
На рис. 4 представлены кривые намагничивания исследованных образцов, измеренные при $5 \mathrm{~K}$ в полях до $90 \mathrm{kOe}$. Намагниченность выражена в магнетонах Бора на формульную единицу (молекулярный магнитный момент $\left.\mu_{m}\right)$.

Молекулярный магнитный момент был рассчитан из полевых зависимостей удельной намагниченности по формуле $\mu_{m}=\sigma A / N_{a} \mu_{\mathrm{B}}$, где $A-$ молярная масса, $N_{a}$ - постоянная Авогадро, $\mu_{\mathrm{B}}-$ магнетон Бора. Как видно, намагниченность большинства образцов не достигает насыщения даже в магнитном поле $90 \mathrm{kOe}$, что свидетельствует о значительной величине магнитокристаллической анизотропии (МКА) [12,15]. Дополнительно причина отсутствия насыщения на кривых намагничивания может быть связана с образованием сперимагнитной структуры при наличии флуктуаций обменных и магнитокристаллических взаимодействий в магнетике, состоящем из двух (или более) магнитных подсистем, связанных между собой отрицательными обменными взаимодействиями [16]. Следует отметить, что намагничивание образца с $x=0.8$ происходит наиболее трудно, что, вероятно, обусловлено парамагнетизмом части атомов кобальта из-за слабости обменного взаимодействия $R-3 d$.

Определение величины магнитного момента на атом гольмия $\left(\mu_{\text {Но }}\right)$ в исследованных интерметаллидах производилось по формуле $\mu_{\mathrm{Ho}}=\left(\mu_{s} \pm \mu_{3 d}\right) /(1-x)$, где $\mu_{3 d}$ - магнитный момент $3 d$-подрешетки, знак „--“, если результирующий магнитный момент соединения в магнитном поле $90 \mathrm{kOe}$ при $5 \mathrm{~K}\left(\mu_{s}\right)$ сонаправлена с намагниченностью $R$-подрешетки, знак „ $+^{\text {“ }}$ - для соединений с преобладанием намагниченностей $3 d$-подрешетки. Значение $\mu_{3 d}$ принималось неизменным во всех соединениях и равным $\mu_{s}$ соединения $\mathrm{Y}\left(\mathrm{Co}_{0.84} \mathrm{Fe}_{0.16}\right)_{2}$. Определенная при таком подходе величина $\mu_{\text {Но }}$ составила $8.8 \mu_{\mathrm{B}}, 9.1 \mu_{\mathrm{B}}$, $9.8 \mu_{\mathrm{B}}, 9.5 \mu_{\mathrm{B}}, 9.6 \mu_{\mathrm{B}}, 7.4 \mu_{\mathrm{B}}$ и $8.3 \mu_{\mathrm{B}}$ соответственно в соединениях с $x=0.0,0.20,0.40,0.60,0.75,0.80$ и 0.85 . Во всех случаях величина оказались ниже таковой для свободного иона $\mathrm{Ho}^{3+}$, равного $10 \mu_{\mathrm{B}}$ [17]. Общая тенденция роста величины $\mu_{\text {Но }}$, при увеличении $x$ от 0.0 до 0.75 , вероятно, обусловлена уменьшением энергии МКА в $R$-подрешетке (эффект разбавления), что приближает значение $\mu_{s}$ к реальной величине намагниченности насыщения этих интерметаллидов. Существенно меньшее его значение в соединении с $x=0.8$, можно объяснить парамагнетизмом части ионов кобальта.

\section{3. Высокополевая восприимчивость}

Для анализа поведения магнитной структуры исследованных соединений в больших магнитных полях во всей магнитоупорядоченной области были рассчитаны температурные зависимости высокополевой восприимчивости $\chi_{h f}(T)$ по формуле $\chi_{h f}=d \sigma / d H$ из линейных участков кривых намагничивания, в диапазоне магнитных полей $20-70 \mathrm{kOe}$, полученные зависимости $\chi_{h f}(T)$ представлены на рис. 5. 


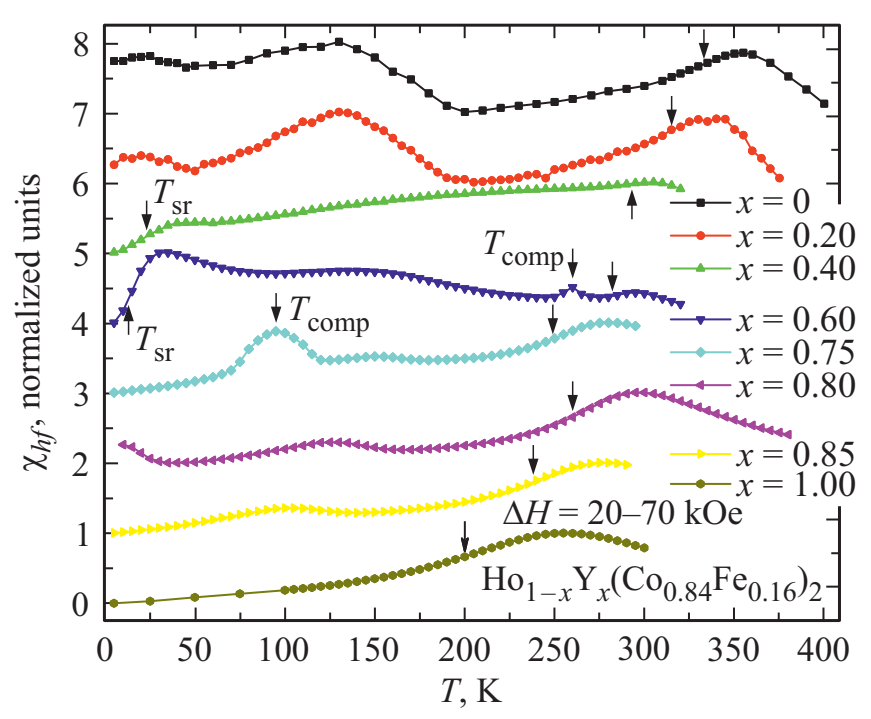

Рис. 5. Температурные зависимости высокополевой восприимчивости $\chi_{h f}(T)$ соединений $\mathrm{Ho}_{1-x} \mathrm{Y}_{x}\left(\mathrm{Co}_{0.84} \mathrm{Fe}_{0.16}\right)_{2}$ в диапазоне изменении внешнего магнитного поля 20-70 kOe. Температуры Кюри отмечены стрелкой без подписи.

На представленных температурных зависимостях $\chi_{h f}(T)$ помимо упомянутых выше пиков, соответствующих магнитным фазовым переходам и точкам магнитной компенсации, отмеченных стрелками, присутствуют „низкотемпературные“ пики в районе $100-130 \mathrm{~K}$. О подобных „низкотемпературных“ пиках на кривых $\chi_{h f}(T)$ сообщалось ранее в родственных соединениях $R(\mathrm{Co}-\mathrm{Fe})_{2} \quad$ с тяжелыми $R \quad[5]$ и в редкоземельных ферритах-гранатах [18]. Данный „низкотемпературный“ пик возникает из-за упорядочения внешним магнитным полем магнитных моментов $R$-ионов, частично разупорядоченных тепловыми флуктуациями вследствие сла- бого обменного взаимодействия между подрешетками $R$ - и $3 d$-ионов. Именно при таких температурах, как при других магнитных фазовых переходах, реализуется значительный отклик подсистемы магнитных моментов $R$-ионов на внешнее магнитное поле, что фактически является фазовым переходом типа порядок-порядок.

Таким образом, в представленных соединениях с гольмием следует ожидать появления нескольких экстремумов на температурных зависимостях магнитного вклада в энтропию $\left(\Delta S_{m}\right)$.

\section{4. Магнитокалорический эффект}

Магнитный вклад в энтропию был рассчитан из серии изотерм намагничивания, с помощью уравнения [19]:

$$
\Delta S_{m}(\Delta H, T)=\int_{0}^{H_{f}}\left(\frac{\partial \sigma}{\partial T}\right)_{H} d H,
$$

где $H_{f}-$ конечное значение магнитного поля, $\Delta H=H_{f}-0$ и $T-$ абсолютная температура. Расчет по формуле (1) проводился с использованием данных полевых зависимостей намагниченности образцов, измеренных с шагом по температуре $5 \mathrm{~K}$ для всех образцов, кроме $\mathrm{Y}\left(\mathrm{Co}_{0.84} \mathrm{Fe}_{0.16}\right)_{2}$, где при температуре $<100 \mathrm{~K}$ шаг составлял $25 \mathrm{~K}$. На рис. 6 представлены температурные зависимости изменения магнитной части энтропии $\Delta S_{m}(T)$ для всех исследованных соединений $\mathrm{Ho}_{1-x} \mathrm{Y}_{x}\left(\mathrm{Co}_{0.84} \mathrm{Fe}_{0.16}\right)_{2}$ при $\Delta H=20 \mathrm{kOe}$ и $70 \mathrm{kOe}$. Как следует из анализа температурных зависимостей высокополевой восприимчивости $\chi_{h f}(T)$, для всех соединений наблюдается несколько экстремумов $\Delta S_{m}$, даже для $\mathrm{Y}\left(\mathrm{Co}_{0.84} \mathrm{Fe}_{0.16}\right)_{2}$.

На образцах с $x \leq 0.4$ есть как пик $\Delta S_{m}$ при $T_{\mathrm{C}}$, так и „низкотемпературный“ пик в окрестности $100 \mathrm{~K}$.
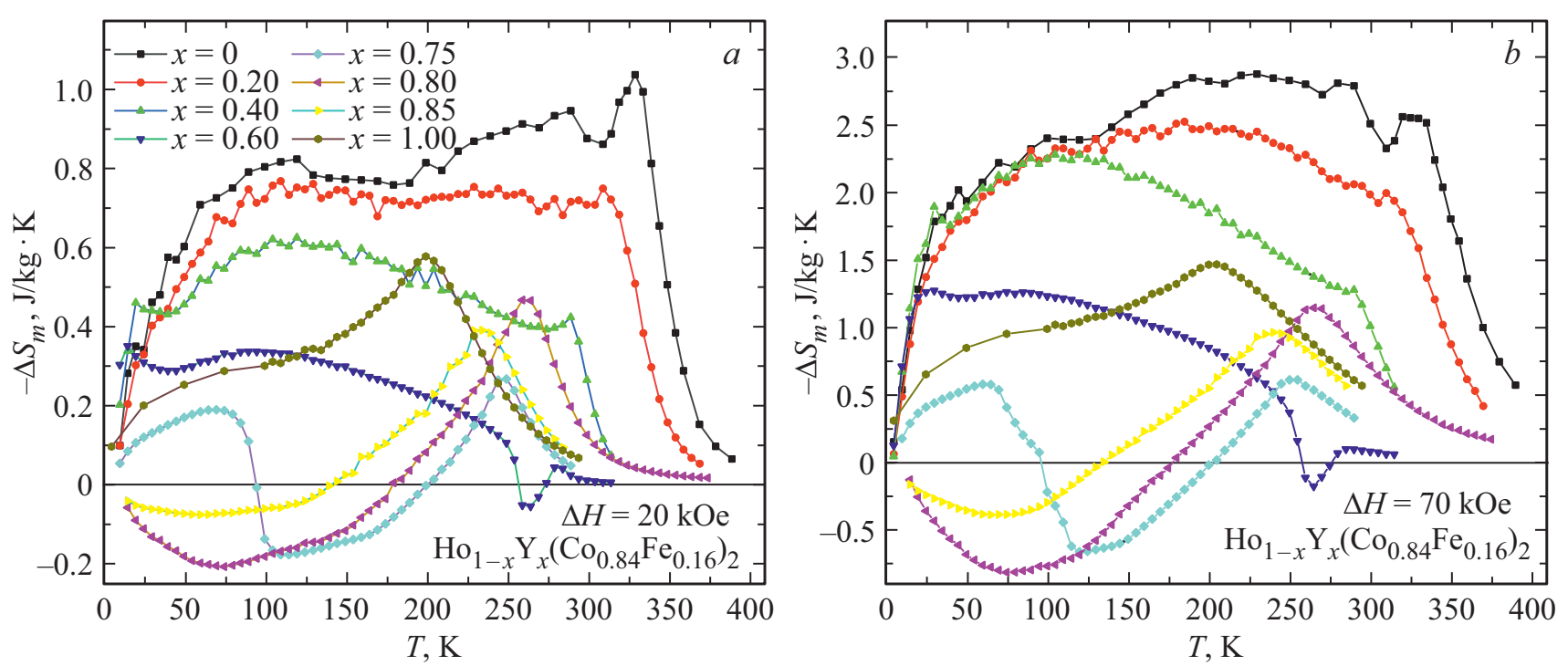

Рис. 6. Температурные зависимости изменения магнитной части энтропии $\Delta S_{m}(T)$ при $\Delta H=20 \mathrm{kOe}(a)$ и $70 \mathrm{kOe}(b)$ для соединений $\mathrm{Ho}_{1-x} \mathrm{Y}_{x}\left(\mathrm{Co}_{0.84} \mathrm{Fe}_{0.16}\right)_{2}$. 
В окрестности $T_{\mathrm{C}}$ значения $\Delta S_{m}$ непрерывно убывают с увеличением содержания иттрия. В то же время, в окрестности $100 \mathrm{~K}$, при $\Delta H=70 \mathrm{kOe}$, значения $\Delta S_{m}$ почти равны. Таким образом, наблюдается более быстрое снижение величин $\Delta S_{m}$ в окрестности $T_{\mathrm{C}}$ в сравнении со значениями $\Delta S_{m}$ в окрестности $100 \mathrm{~K}$, что можно объяснить, если принять во внимание, что энергия $4 f-3 d$ межподрешеточного обменного взаимодействия быстро уменьшается с увеличением содержания иттрия. Для составов с большим содержанием иттрия степень магнитного разупорядочения $4 f$-подсистемы в окрестности „низкотемпературного“ максимума будет наибольшая, это отражается в большем магнитном вкладе в энтропию соединений. В окрестности температуры Кюри МКЭ обусловлен как $4 f$-подрешеткой, так и $3 d$-подрешеткой, имеющих разные знаки. Из-за уменьшения доли Но при увеличении $x$ снижается прямой МКЭ, связанный с изменением намагниченности $4 f$-подрешетки, из которого вычитается обратный МКЭ, связанный с изменением намагниченности $3 d$-подрешетки [20], где количество атомов Со и $\mathrm{Fe}$ неизменно, следовательно, обратный МКЭ должен быть практически постоянным для разных $x$.

На зависимости $\Delta S_{m}(T)$ для соединений с $x=0.4$ и 0.6 , наглядно виден пик $\Delta S_{m}$, соответсвующий спинпереориентационному переходу.

В соединениях с $x=0.6$ и 0.75 , обладающих точкой магнитной компенсации, с увеличением температуры последовательно наблюдаются прямой МКЭ ниже $T_{\text {comp}}$, обратный МКЭ выше $T_{\text {comp }}$ и снова прямой МКЭ при приближении к $T_{\mathrm{C}}$. Физическая причина изменения знака при переходе через точку магнитной компенсации подробно описана в работе [20].

Обратный и прямой МКЭ наблюдается и на зависимости $\Delta S_{m}(T)$ в соединениях с $x=0.8$ и 0.75 . Вид зависимости $\Delta S_{m}(T)$ сопоставим с таковым для состава с $x=0.75$ в области температур выше $T_{\text {comp. }}$.

В соединении с немагнитным иттрием, кроме пика $\Delta S_{m}$ в окрестности $T_{\mathrm{C}}$, наблюдается платоподобная зависимость при температурах ниже $T_{\mathrm{C}}$. Предположительно, наличие МКЭ при температурах ниже $T_{\mathrm{C}}$ может быть связано с парамагнетизмом части атомов кобальта в данном соединении.

На рис. 7 представлены температурные зависимости адиабатического изменения температуры $\left(\Delta T_{a d}\right)$ исследованных образцов, измеренные прямым способом. Зависимости $\Delta T_{a d}(T)$ для соединений с $x \geq 0.4$ являются усреднением экспериментальных данных. Отклонение экспериментальных данных не превышает $\pm 0.06 \mathrm{~K}$ от усредненной зависимости. Больший разброс экспериментальных значений наблюдался на участках зависимости $\Delta T_{a d}(T)$ соответствующих обратному МКЭ, где отклонение экспериментальных данных достигало $\pm 0.15 \mathrm{~K}$, в связи с чем данные участки зависимости $\Delta T_{a d}(T)$ должны рассматриваться как качественный результат.

Из сравнения температурных зависимостей $\Delta T_{a d}(T)$ при $\Delta H=17.5 \mathrm{kOe}$ и $\Delta S_{m}(T)$ при $\Delta H=20 \mathrm{kOe}$, следует,

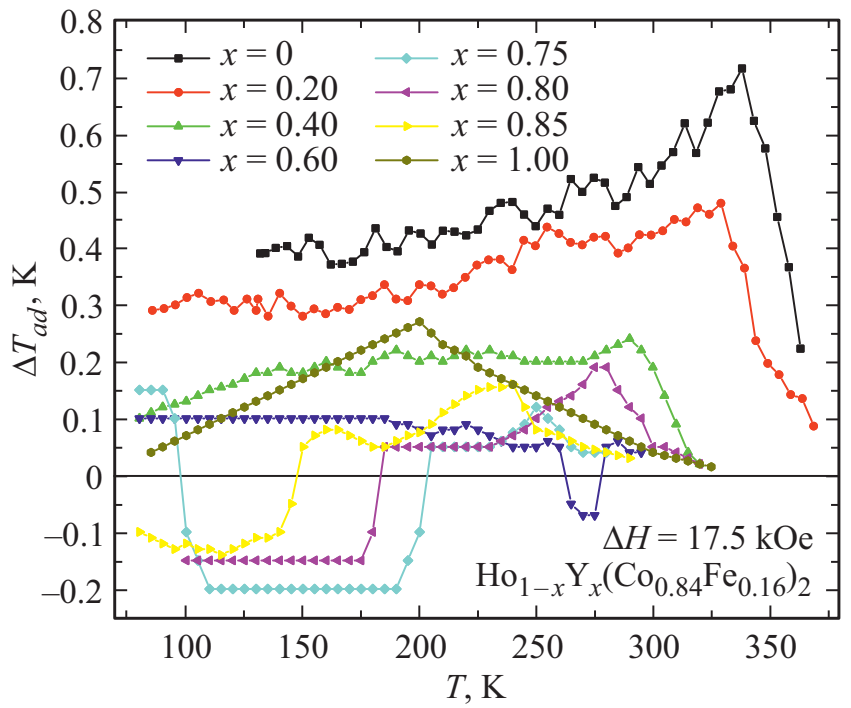

Рис. 7. Температурные зависимости адиабатического изменения температуры $\Delta T_{a d}(T)$ при $\Delta H=17.5 \mathrm{kOe}$ для соединений $\mathrm{Ho}_{1-x} \mathrm{Y}_{x}\left(\mathrm{Co}_{0.84} \mathrm{Fe}_{0.16}\right)_{2}$.

что они качественно идентичны. В частности, присутствует выраженная платоподобная зависимость МКЭ на образцах с $x \leq 0.6$, и чередование прямого и обратного МКЭ на образцах с $x=0.6-0.85$. Главным отличием является относительная величина МКЭ в окрестности $100 \mathrm{~K}$. Например, для состава с $x=0.4 \Delta S_{m}$ при температуре $100 \mathrm{~K}$ больше, чем при $T_{\mathrm{C}}$, а значение $\Delta T_{a d}$, наоборот, больше при $T_{\mathrm{C}}$.

\section{4. Заключение}

Таким образом, при замещении магнитного $\mathrm{Ho}^{3+}$ на „немагнитный“ $\mathrm{Y}^{3+}$ в системе $\mathrm{Ho}_{1-x} \mathrm{Y}_{x}\left(\mathrm{Co}_{0.84} \mathrm{Fe}_{0.16}\right)_{2}$ поочередно реализуются три ферри- и одна ферромагнитная структуры. Для каждого типа магнитной структуры характерны свои температурные зависимости удельной намагниченности $(\sigma)$, высокополевой восприимчивости $\left(\chi_{h f}\right)$, изменения магнитной части энтропии $\left(\Delta S_{m}\right)$ и адиабатического изменения температуры $\left(\Delta T_{a d}\right)$.

Параметр кристаллической решетки $(a)$ при увеличении содержания иттрия $(x)$ имеет общую тенденцию к увеличению, а концентрационная зависимость $T_{\mathrm{C}}-\mathrm{\kappa}$ уменьшению. При этом на обеих зависимостях наблюдаются локальные отклонения от общей тенденции для составов с $x=0.75$ и 0.8 . В то же время, из анализа концентрационных зависимостей $\mu_{m}(H), \mu_{s}, \Delta T_{a d}(T)$ и $\Delta S_{m}(T)$ следует, что данные соединения соответствуют своему составу, а отклонения на концентрационных зависимостях $a$ и $T_{\mathrm{C}}$ могут быть связаны с неоднородным размещением атомов гольмия и иттрия по узлам кубической кристаллической решетки $8 b$.

Величина $\Delta S_{m}$ в окрестности $100 \mathrm{~K}$ при $\Delta H=70 \mathrm{kOe}$, остается постоянной даже при замещении $40 \%$ Но на Y в $\mathrm{Ho}\left(\mathrm{Co}_{0.84} \mathrm{Fe}_{0.16}\right)_{2}$, в то же время уменьшается в 2 раза в окрестности $T_{\mathrm{C}}$. 


\section{Финансирование работы}

Исследование выполнено за счет гранта Российского научного фонда (проект № 19-72-00038).

\section{Конфликт интересов}

Авторы заявляют, что у них нет конфликта интересов.

\section{Список литературы}

[1] S.A. Nikitin, A.M. Tishin. Cryogenics 31, 3, 166 (1991).

[2] A. Giguere, M. Foldeaki, W. Schnelle, E. Gmelin. J. Phys.: Condens. Matter 11, 6969 (1999).

[3] N.H. Duc, D.T. Kim Anh. J. Magn. Magn. Mater. 242-245, 873 (2002).

[4] L. Li, K. Nishimura, D. Tamei, K. Mori. Solid State Commun. 145, 427 (2008).

[5] M. Anikin, E. Tarasov, N. Kudrevatykh, A. Inishev, M. Semkin, A. Volegov, A. Zinin. J. Magn. Magn. Mater. 418, 181 (2016).

[6] M. Anikin, E. Tarasov, N. Kudrevatykh, A. Inishev, M. Semkin, A. Volegov, A. Zinin. J. Magn. Magn. Mater. 449, 353 (2018).

[7] М.С. Аникин, Е.Н. Тарасов, Н.В. Кудреватых, А.А. Инишев, А.В. Зинин. МиТОМ. 8, 36 (2018).

[8] E. Belorizky, M.A. Fremy, J.P. Gavigan, D. Givord, H.S. Li. J. Appl. Phys. 61, 3971 (1987).

[9] J. Rodriguez-Carvajal. Phys. B 192, 55 (1993).

[10] K.N.R. Taylor. Adv. Phys. 20, 551 (1971).

[11] S.H. Kilcoyne. Physica B 276-278, 660 (2000).

[12] D. Gignoux, F. Givord, R. Lemaire. Phys. Rev. B: Condens. Matter 12, 9, 3878 (1975).

[13] M. Khan, D. Paudya, K.A. Gschneidner, Jr., V.K. Pecharsky. J. Appl. Phys. 113, 17E106 (2013).

[14] R. Mondal, R. Nirmala, J. Arout Chelvane, A.K. Nigam. Physica B 448, 9 (2014).

[15] Н.В. Кудреватых, В.Н. Москалев, А.В. Дерягин, А.В. Андреев, С.М. Задворкин. Укр. физ. журн. 26, 1734 (1981).

[16] С.А. Никитин. Магнитные свойства редкоземельных металлов и их сплавов. МГУ, М. (1989). 248 с.

[17] M.S.S. Brooks, L. Nordstrom, B. Johansson. J. Phys.: Condens. Matter 3, 2357 (1991).

[18] К.П. Белов. УФН 166, 669 (1996).

[19] K.A. Gschneidner Jr., V.K. Pecharsky. Annu. Rev. Mater. Sci. 30, 387 (2000).

[20] А.С. Андреенко, К.П. Белов, С.А. Никитин, А.М. Тишин. Усп. физ. наук. 158, 553 (1989).

Редактор Ю.Э. Китаев 